\title{
Counselors, Social Workers, and Other Community and Social Service Specialists
}

National Cancer Institute

\section{Source}

National Cancer Institute. Counselors, Social Workers, and Other Community and Social

Service Specialists. NCI Thesaurus. Code C122441.

Workers who make arrangements for needed services and treatments for individuals and families and/or develop and implement specialized treatment programs within a community. Others provide front line support and social assistance for individuals, families, and communities in need. 